the virulent leaf rust fungus, to show that traditional, allegedly outmoded forms of land use may help to solve modern environmental problems. The opposing side advocates modern, technology-intensive, high-performance forms of agriculture that safeguard large parts of the world's food supply today, but are not resilient and depend on significant inputs of fossil fuels that may become expensive in the future.

Nabhan notes the often overlooked contributions of traditional ecological knowledge to sustainable food production. After reading the book, major questions arise. Do locally domesticated plants have an archival function that provides genetic varieties for modern plant breeding, and should they thus be conserved in their remote centres of origin? Or can they be used on a larger scale in intensive agricultural landscapes? The integration of traditional and modern practices into agricultural systems that are productive yet sustainable, consideration of the needs of small-scale farmers and maintenance of diverse ecosystems will all remain conflict-laden - but they represent crucial challenges in the quest to feed the world. Tobias Plieninger heads a group on ecosystem services at the Berlin-Brandenburg Academy of Sciences and Humanities, Jägerstrasse 22/23, 10117 Berlin, Germany. e-mail: plieninger@bbaw.de

\title{
Early days of science broadcasting
}

\section{Science on the Air: Popularizers and Personalities on Radio and Early Television by Marcel Chotkowski LaFollette Chicago Univ. Press: 2008. 324 pp. $\$ 27.50$}

Writing popular science and writing about popular science are very different endeavours. The former is at least as old as John Newbery's Newtonian System of Philosophy (1761), with its star Tom Telescope, and has been practised in every medium in turn: lectures, books, newspapers, magazines, cinema, radio, television and the Internet. But analysing it is a recent pursuit, tied to the growth of university sciencestudies departments concerned with science's social dimensions. Although now established, the field is not so overpopulated that there is agreement about how to do it, or for whom.

Marcel Chotkowski LaFollette has written on the history of popular science for more than 25 years, and is best known for Making Science our Own: Public Images of Science, 1910-1955 (Univ. Chicago Press, 1990). In her new book, Science on the Air, she reveals from primary sources the story of the first 20 years of science broadcasting on US radio. We meet the Smithsonian Institution's Austin Hobart Clark, who initiated a series of scientists' radio lectures in 1923, and Thornton Burgess, who transferred from writing children's nature books to radio programmes. LaFollette discusses how the scientist William Ritter and the newspaper

publisher Edward Scripps established the Science Service news bureau in 1920, which was highly influential in both print and radio for four decades. The one post-war chapter, which benefits from an established secondary literature, discusses science on US television in the 1940s and 1950s. Here LaFollette con-
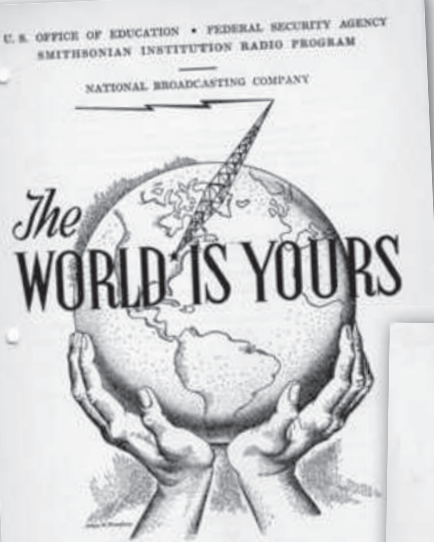

March of Science

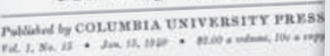
trasts the sober style of The Johns Hopkins Science Review (from 1948) with the more entertaining formats sponsored by the Bell Telephone System and programmes made by Disney from 1954.

argumentative or analytical approach would have addressed why popular science matters.

The relationship of science to people and to the broader culture was, in the period she describes, gaining importance as the sciences began to have a significant impact on ordinary lives. The possibility that scientists might have a negative impact, through their perceived responsibility for new weapons and mass-production machinery, was a live issue. More historical studies of the vehicles of science communication are needed so that we can understand the interplay between science and society; but this requires more than narrative.

So little is published in this area that it would be unfair to ask LaFollette to draw international comparisons. With a myriad of local commercial stations to follow and many potential stories to tell, she has a more difficult job than scholars of British science radio, for example, where for the same period there was one monopoly broadcaster, the BBC. LaFollette describes how in the United States scientists preferred a lecture format, but were put under pressure to make their programmes more entertaining or risk marginalization. In Britain, producers remained deferential and accepted that information should be conveyed directly from the authority to the viewer "public men personally discussing events in the news", as one producer put it. Unlike in the United States, elite scientific organizations such as the Royal Society and the British Association repeatedly sought control over broadcasts. A common element was the growing importance of the skilled intermediary, and mediation by a presenter was the norm on television by the late 1950 s.

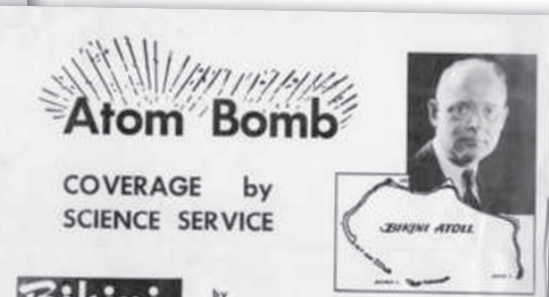

Bikini De mang BHONt Retogiv

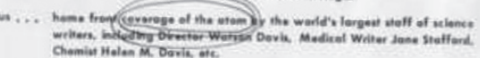

Scientists conveyed information directly to the public in early radio broadcasts.

Science on the Air has an academic level of detail. But LaFollette writes in a narrative style, with occasional touches of whimsy "microphones trembled during atomic bomb tests and rattled with impassioned debate", for example. This choice has consequences; after reading it, you will know what happened to US science radio and early television, but you may wonder why you need to know it. A more
Today the media market is global. Producers work in a multichannel world, where no country's output can afford to limit itself to national concerns. Single broadcasters can rarely afford the cost of ambitious science shows and so seek to collaborate. Co-production has led to a homogenization of style, moving closer to the US entertainment model and away from the earnest, deferential treatment LaFollette describes in 1920s radio. Some commentators fear that the science in science programming is reaching homeopathic concentration. The continuing presence of science in the schedules, evidently vulnerable to broadcasting fashions, demands investigation. This book shows it can be done.

Tim Boon is chief curator at the Science Museum, London, and author of Films of Fact: A History of Science in Documentary Films and Television. 